Article

\title{
Regulating carbon work function to boost electrocatalytic activity for the oxygen reduction reaction
}

\author{
Yazhi Cai, Li Tao, Gen Huang, Nana Zhang, Yuqin Zou *, Shuangyin Wang \\ State Key Laboratory of Chem/Bio-Sensing and Chemometrics, Provincial Hunan Key Laboratory for Graphene Materials and Devices, \\ College of Chemistry and Chemical Engineering, Hunan University, Changsha 410082, Hunan, China
}

\section{A R T I C L E I N F O}

\section{Article history:}

Received 11 May 2020

Accepted 6 July 2020

Published 22 November 2020

\section{Keywords:}

Cesium doping

Nitrogen-doped carbon

Electronic regulation

Work function

Oxygen reduction reaction

\begin{abstract}
A B S T R A C T
Electronic regulation of carbon is essential for developing non-platinum electrocatalysts for oxygen reduction reactions (ORRs). In this work, we used Cs to further regulate the electronic structure of nitrogen-doped (N-doped) carbon. The Cs atoms coordinated with the nitrogen atom in the $\mathrm{N}$-doped carbon for injecting electrons into the carbon conjugate structure and reducing the work function of the carbon network. The low-work-function surface improved electron donation, facilitated $\mathrm{O}_{2}$ dissociation, and enhanced the adsorption of an $\mathrm{OOH}^{*}$ intermediate. Thus, electrocatalytic performance for the ORR was improved. The material shows potential as an ORR electrocatalyst comparable with Pt/C.
\end{abstract}

(c) 2021, Dalian Institute of Chemical Physics, Chinese Academy of Sciences. Published by Elsevier B.V. All rights reserved.

Work function is defined as the minimum amount of energy required to remove an electron from the surface, reflecting the electron-donating ability of a solid [8]. Electrons are more likely to escape from the surface of a material with a low work function and participate in the reduction reaction on the electrode surface [9]. Lou et al. [10] discovered that $\mathrm{Bi}_{2} \mathrm{O}_{3}$ nanosheets with a low work function showed improved electrocatalytic performance in the $\mathrm{CO}_{2}$ reduction reaction. The work function also contributes significantly to the ORR. Yang et al. [11] reported that, based on the density functional theory, the energy barrier of oxygen-molecule dissociation is related to the partial occupation of $p^{*}$ orbitals and change of work functions on a carbon nanotube or graphene with different types of $\mathrm{N}$-doping. Moreover, the authors claimed that graphitic $\mathrm{N}$ is more important than pyridinic $\mathrm{N}$ for ORR because the former has a lower work function and smaller $\mathrm{O}_{2}$ dissociation barrier. Joo's group provided the first direct experimental evidence that

\footnotetext{
* Corresponding author. E-mail: yuqin_zou@hnu.edu.cn

This work was supported by the Fundamental Research Funds for the Central Universities (531118010127), the National Natural Science Foundation of China (21902047, 51402100, 21825201, 21573066, 21805080), and the Provincial Natural Science Foundation of Hunan (2016TP1009). DOI: 10.1016/S1872-2067(20)63701-9 | http://www.sciencedirect.com/science/journal/18722067 | Chin. J. Catal., Vol. 42, No. 6, June 2021
} 
the nanoscale work function of doped nanocarbon, measured by Kelvin probe force microscopy (KPFM), is intrinsically correlated with ORR activity and reaction kinetics of doped nanocarbon catalysts [12]. Thereafter, Sung et al. [13] investigated the relationship between ORR activities and work functions of sulfur-doped carbon catalysts. They demonstrated the high applicability of work function as the activity descriptor. These efforts have inspired us to search for efficient oxygen reduction catalysts with a low work function.

In this study, we introduced cesium as the modifier to lower the work function of $\mathrm{N}$-doped carbon by adding cesium carbonate in the synthetic processes of zeolite imidazolate frameworks. Cesium carbonate, an efficient electron-injection material, is a well-known substance that reduces surface work function. It is widely used in organic light-emitting diodes (OLEDs), including those based on small molecules and polymers (polymer light-emitting diodes (PLEDs)) [14]. After high-temperature pyrolysis, we successfully obtained cesium-modified, N-doped ultrathin carbon nanosheet networks. The cesium was embedded in the carbon layer and coordinated with the nitrogen atoms around it, successfully reducing the surface work function of the carbon from 4.15 to $3.6 \mathrm{eV}$, thus ensuring excellent ORR activity.

\section{Experimental}

\subsection{Materials}

Zinc nitrate hexahydrate $\left(\mathrm{Zn}\left(\mathrm{NO}_{3}\right)_{2} \cdot 6 \mathrm{H}_{2} \mathrm{O}\right)$, 2-methylimidazole (MeIM), cesium carbonate $\left(\mathrm{Cs}_{2} \mathrm{CO}_{3}\right)$ were obtained from Shanghai Chemical Reagents, China. Commercial $\mathrm{Pt} / \mathrm{C}$ catalyst (20 wt\%) was obtained from Johnson Matthey and Nafion was obtained from Sigma-Aldrich. All chemicals used in this experiment were used without further purification.

\subsection{Preparation of $\mathrm{N} / \mathrm{C}$}

Typically, the molar ratio of $\mathrm{Zn}\left(\mathrm{NO}_{3}\right)_{2} \cdot 6 \mathrm{H}_{2} \mathrm{O}$ and MeIM was 1:2. The mixture was ground together in an agate mortar for 5 min. Next, the precursors were transferred into a quartz boat and placed inside a tube furnace. The furnace was heated with a heating ramp of $5{ }^{\circ} \mathrm{C} \mathrm{min}-1$ and maintained at $150{ }^{\circ} \mathrm{C}$ for $2 \mathrm{~h}$, then heated to $800^{\circ} \mathrm{C}$ for $6 \mathrm{~h}$ under continuous Ar.

\subsection{Preparation of $C s-N / C$}

$\mathrm{Zn}\left(\mathrm{NO}_{3}\right)_{2} \cdot 6 \mathrm{H}_{2} \mathrm{O}, \mathrm{MeIM}$, and $\mathrm{Cs}_{2} \mathrm{CO}_{3}$ were ground together in an agate mortar for $5 \mathrm{~min}$. The molar ratio of $\mathrm{Zn}\left(\mathrm{NO}_{3}\right)_{2} \cdot 6 \mathrm{H}_{2} \mathrm{O}$ and MeIM remained 1:2 and the contents of cesium carbonate were controlled to be $4.15 \%, 11.5 \%$ and $17.8 \%$. The newly-formed precursors were transfer into a quartz boat to undergo pyrolysis. The furnace was also heated with a heating ramp of $5{ }^{\circ} \mathrm{C} \mathrm{min}^{-1}$ and maintained at $150{ }^{\circ} \mathrm{C}$ for $2 \mathrm{~h}$, then heated to $800{ }^{\circ} \mathrm{C}$ for $6 \mathrm{~h}$ under continuous Ar. The control experiments were also performed by annealing the Cs-ZIF precursors at $150,600,700,800,900$ and $1000{ }^{\circ} \mathrm{C}$, and the corresponding products were named as Cs-N/C-150, Cs-N/C-600, Cs-N/C-700,
Cs-N/C-800, Cs-N/C-900, Cs-N/C-1000, respectively. After cooling down to room temperature naturally, the products were washed with deionized water several times to eliminate free Cs species thoroughly, and were dried overnight to yield carbon power. The corresponding sample with the $\mathrm{Cs}_{2} \mathrm{CO}_{3}$ content of $11.5 \%$ and annealed at $800{ }^{\circ} \mathrm{C}$ for $6 \mathrm{~h}$ was also named Cs-N/C.

\subsection{Characterization}

Microstructure features of all electrocatalysts were investigated by scanning electron microscopy (SEM, Hitachi, S-4800), and transmission electron microscope (TEM, FEI Tecnai G20). The crystal structures of the samples were characterized using powder X-ray diffraction (XRD, Bruker D8 Advance diffractometer, $\mathrm{Cu}-K_{\alpha}$ ). X-ray photoelectron spectroscopic (XPS) was carried out on an ESCALAB 250Xi with an Al $K_{\alpha}$ radiator. The surface work function of the samples was analyzed by ultraviolet photoelectron spectroscopy (UPS) (ThermoFisher ESCALAB 250Xi). The Brunauer-Emmett-Teller (BET) specific surface area was measured at $77 \mathrm{~K}$ using the sophisticated JW-BK200C. Raman spectra were collected on a Raman spectrometer (Labram-010) using $632 \mathrm{~nm}$ laser. The TGA (STA449C) was carried out from the $50{ }^{\circ} \mathrm{C}$ to $1000^{\circ} \mathrm{C}$ in $\mathrm{Ar}$ ambience.

\subsection{Electrochemical measurements}

The electrochemical measurements were performed in a three-electrode system using an electrochemical workstation (CHI 760E). A catalyst coated glassy carbon rotating disk electrode was used as the working electrode, and a carbon rod and the saturated calomel electrode (SCE) were used as the counter electrode and the reference electrode, respectively. For the preparation of catalyst ink, $2 \mathrm{mg}$ catalyst was dispersed in $1 \mathrm{ml}$ ethanol. Then $50 \mu \mathrm{l}$ 5\% Nafion solution was added to the dispersion to form a homogenous ink. The working electrode with a mass loading of $0.2 \mathrm{mg} \mathrm{cm}^{-2}$ was prepared by dripping $13 \mu \mathrm{l}$ catalytic ink on a well-polished glassy carbon (4 $\mathrm{mm}$ in diameter) and dried under ambient conditions. Before tests, $\mathrm{N}_{2} / \mathrm{O}_{2}$ flow was carried out through the electrolyte in the cell for about 30 min to achieve the $\mathrm{Ar} / \mathrm{O}_{2}$ saturated solution. The cyclic voltammetry (CV) tests were measured in $\mathrm{N}_{2}$ and $\mathrm{O}_{2}$ saturated $0.1 \mathrm{M} \mathrm{KOH}$ solution with a scan rate of $50 \mathrm{mV} \mathrm{s}^{-1}$. Rotating disk electrode (RDE) and Rotating ring-disk electrode (RRDE) tests were conducted in $\mathrm{O}_{2}$ saturated $0.1 \mathrm{M} \mathrm{KOH}$ with a sweep rate of $10 \mathrm{mV} \mathrm{s}^{-1} .20 \mathrm{wt} \% \mathrm{Pt} / \mathrm{C}$ catalysts with the same mass loading was also studied for comparison. EIS tests were conducted with a sinusoidal voltage with amplitude of $10 \mathrm{mV}$ and a scanning frequency from $100 \mathrm{kHz}$ to $0.01 \mathrm{~Hz}$ was applied.

\subsection{Calculations}

RRDE results were used to calculate the transferred electron number $(n)$ as well as the $\mathrm{H}_{2} \mathrm{O}_{2}$ production yield according to the following formulas: 


$$
\begin{gathered}
n=\frac{4 I_{d}}{\frac{I_{r}}{N}+I_{d}} \\
H_{2} O_{2} \%=100 \times \frac{4-n}{2}
\end{gathered}
$$

where $n$ is the electron transfer number during the ORR process, $I_{\mathrm{d}}$ is the absolute value of the disk current, $I_{\mathrm{r}}$ is the absolute value of the ring current, and $N$ is the current collection efficiency of Pt ring ( 0.38 in this work).

RDE measurement was used to calculate the kinetic current density $\left(j_{\mathrm{k}}\right)$ according to the Koutecky-Levich equation given below

$$
\begin{gathered}
\frac{1}{j}=\frac{1}{B \omega^{0.5}}+\frac{1}{j_{k}} \\
B=0.2 n F c_{0} D_{0}{ }^{2 / 3} v^{-1 / 6}
\end{gathered}
$$

where $J_{K}$ is the kinetic current and $\omega$ is the electrode rotating rate. $B$ could be determined from the slope of the K-L plots, $n$ is the number of electrons transferred per oxygen molecule, $F$ is the Faradaic constant $\left(96485 \mathrm{C} \mathrm{mol}^{-1}\right), D_{0}$ is the diffusion coefficient of $\mathrm{O}_{2}$ in $0.1 \mathrm{~m} \mathrm{KOH}\left(1.9 \times 10^{-5} \mathrm{~cm}^{2} \mathrm{~s}^{-1}\right), v$ is the kinetic viscosity of the electrolyte $\left(0.01 \mathrm{~cm}^{2} \mathrm{~s}^{-1}\right)$, and $c_{0}$ is the bulk concentration of $\mathrm{O}_{2}\left(1.2 \times 10^{-6} \mathrm{~mol} \mathrm{~cm}^{-3}\right)$. The constant 0.2 is adopted when the rotation speed is expressed in rpm. The RHE calibration was conducted. In this study, $E(\mathrm{RHE})=E(\mathrm{SCE})+$ $0.99 \mathrm{~V}$. The onset potential was calculated according to $5 \%$ of the limiting current. The half-way potential was calculated according to $50 \%$ of the limiting current.

\section{Results and discussion}

The cesium-modified, N-doped ultrathin carbon nanosheet networks, denoted as Cs-N/C, were prepared by direct pyrolysis of a mechanically ground mixture of zinc nitrate hexahydrate, 2-methylimidazole, and cesium carbonate under Ar atmosphere at $150{ }^{\circ} \mathrm{C}$ for $2 \mathrm{~h}$ and then at $800{ }^{\circ} \mathrm{C}$ for $6 \mathrm{~h}$. The synthesis was quite similar to that of the pristine N/C, except for the addition of $\mathrm{Cs}_{2} \mathrm{CO}_{3}$ (Scheme 1). We varied the mass of cesium salts and the pyrolysis temperature in the preparation procedure, then determined that using $11.5 \% \mathrm{Cs}_{2} \mathrm{CO}_{3}$ at a calcination temperature of $800{ }^{\circ} \mathrm{C}$ was the optimal preparation condition (Figs. S1 and S2). Thermogravimetric analysis was performed to monitor the decomposition and transformation process of both Cs-N/C and N/C at a heating rate of $3{ }^{\circ} \mathrm{C} \mathrm{min}-1$ in the $\mathrm{Ar}$ atmosphere (Fig. S3). The imidazole structure dehydrated and swelled at about $150{ }^{\circ} \mathrm{C}$, then gradually carbonized as the temperature rose, forming carbon aerogel (Fig. S4).

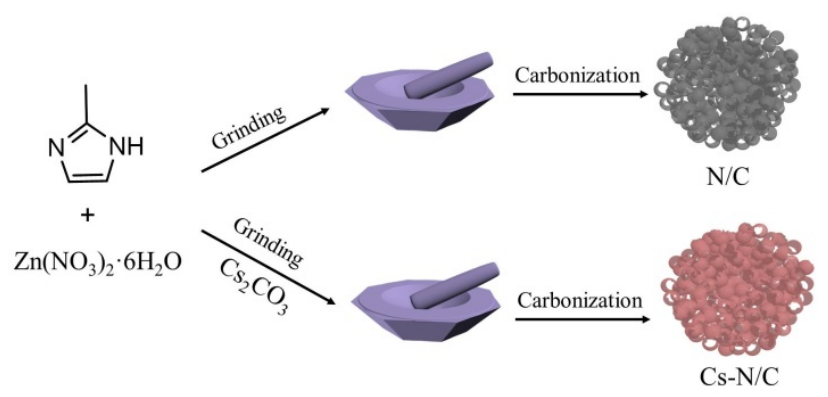

Scheme 1. Schematic illustrations of the preparation of the Cs-N/C and N/C.
The surface morphology and microstructure of the Cs-N/C and N/C were characterized using scanning electron microscopy (SEM) and transmission electron microscopy (TEM). Figs. 1(a) and Fig. 1(b) show that the Cs-N/C retained the shape of the N/C after cesium-doping - that is, a 3D carbon network consisting of macropores interconnected with carbon nanosheets (Fig. 1(c)). The morphology of the 3D carbon network enhanced electron and mass transport. A high-resolution TEM (HRTEM) image (Fig. 1(d)) revealed that the carbon nanosheets comprised a disordered carbon structure, with a low degree of graphitization and plenty of defects serving as active sites for ORR. The mapping images (Fig. 1(e)) showed that the cesium, carbon, oxygen, and nitrogen atoms were distributed uniformly over the entire carbon nanosheet. There was no formation of metallic aggregates, which would indicate atomic cesium sites. Furthermore, since the unstable cesium on the surface was washed away by water, the remaining cesium was buried into carbon layers.

The carbon samples were characterized by powder X-ray diffraction (PXRD) (Fig. 2(a)). Only a broad (002) basal plane diffraction of carbon was observed for $\mathrm{Cs}-\mathrm{N} / \mathrm{C}$; the zinc-related peaks were gone, unlike in the Cs-N/C-600 (Fig. S5), indicating the complete evaporation of zinc and, more importantly, the atomically distributed cesium-containing species. Meanwhile, the (002) peak of the Cs-N/C was weaker than the N/C, which may be attributed to the structural disorder and defects generated after doping with $\mathrm{Cs}_{2} \mathrm{CO}_{3}$. This finding was also confirmed by the BET data in Fig. S6, as estimated by the nitrogen adsorption/desorption method, where Cs-N/C exhibited a larger surface area $\left(856.15 \mathrm{~m}^{2} \mathrm{~g}^{-1}\right)$ than N/C $\left(624.51 \mathrm{~m}^{2} \mathrm{~g}^{-1}\right)$. The decomposition of carbonate destroyed the crystallinity of the material after the cesium doping. More defects were generated, which was beneficial to the ORR.

Fig. 2(d) shows the Raman spectra of the Cs-N/C and N/C. The $\mathrm{G}$ band at around $1589 \mathrm{~cm}^{-1}$ corresponds to the in-plane vibration of $s p^{2}$ carbon. Compared to the N/C, the G band of the Cs-N/C was upshifted by $12 \mathrm{~cm}^{-1}$ in wavelength. Electron doping on carbon has been reported to cause the shift of the $\mathrm{G}$ band [15]. Therefore, the large peak shift of the G band of the Cs-N/C suggests a strong electronic modification of carbon after cesium doping. In sum, cesium carbonate injected electrons into the carbon conjugate structure, the electron density of the carbon plane increased, and the $\mathrm{G}$ band shifted.

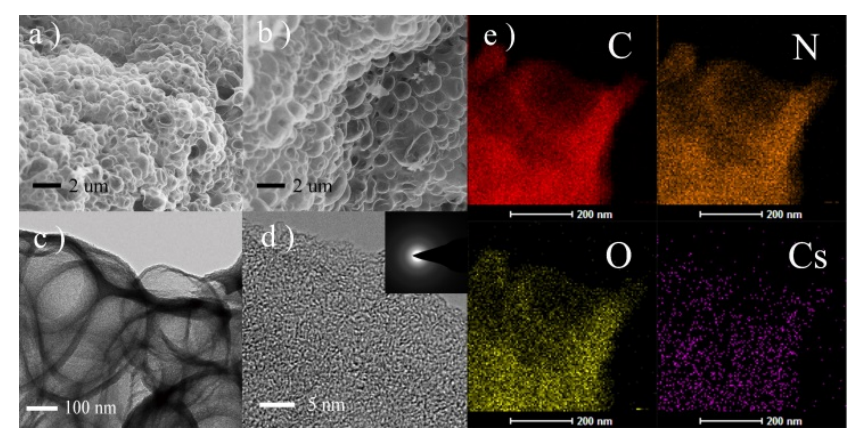

Fig. 1. SEM images of Cs-N/C (a) and N/C (b); (c) TEM image of Cs-N/C; (d) HRTEM image of Cs-N/C (inset in (d) shows SAED pattern of Cs-N/C); (e) EDS elemental mapping images of Cs-N/C. 

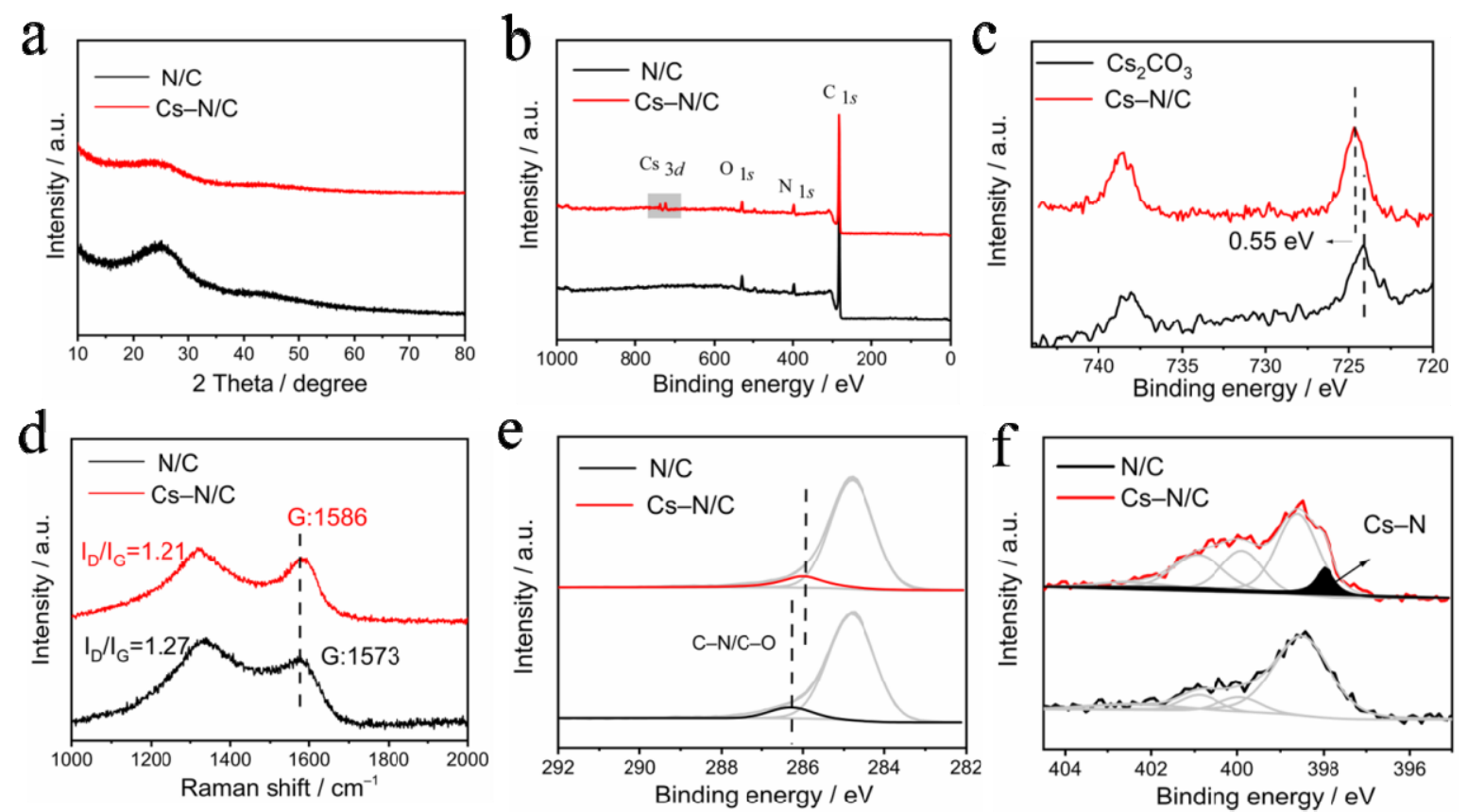

Fig. 2. (a) XRD patterns for Cs-N/C and N/C; (b) XPS survey for Cs-N/C and N/C; (c) Cs 3d spectra for Cs-N/C and $\mathrm{Cs}_{2} \mathrm{CO}_{3}$; (d) Raman spectra for Cs-N/C and N/C; (e) C $1 s$ spectra for N/C and Cs-N/C; (f) N $1 s$ spectra for N/C and Cs-N/C.

To determine the form of cesium species and clarify the electronic structure of the carbon, X-ray photoelectron spectroscopy (XPS) was carried out. The XPS survey spectra of the Cs-N/C and N/C are compared in Fig. 2(c). Both porous carbons show the nitrogen $1 s$, carbon $1 s$, and oxygen $1 s$ peaks [3]; a single peak of cesium [16] was found in only the Cs-N/C at $\sim 710$ eV. Fig. 2(c) shows the cesium 3D signals of the Cs-N/C and $\mathrm{Cs}_{2} \mathrm{CO}_{3}$ precursors. The signature peak of the cesium $3 \mathrm{D}$ energy level shifted to higher binding energy after incorporation into the carbon skeleton - a conclusive indication that cesium atoms donated electrons to the surrounding chemical environment [17].

To gain further insight into the chemical reaction between the $\mathrm{Cs}_{2} \mathrm{CO}_{3}$ and ZIF structure, we also used XPS to monitor the chemical shift of the cesium 3D signals of Cs-N/C that had been subjected to annealing at various temperatures. Fig. S7 reveals that the cesium 3D signal gradually shifted to higher binding energy as the temperature slowly increased to $150^{\circ} \mathrm{C}$. The XRD pattern (Fig. S5) of the Cs-N/C-150 also showed no cesium-related peaks, indicating the disintegration of cesium carbonate and interaction of cesium-imidazole structure. The higher temperature led to the higher ion valence level of the cesium with enhanced electron-injection properties [17]. Cesium carbonate is strongly alkaline, thus, if too much is added, the structure of the MOF would be directly destroyed. In this work, the Cs-N/C with the doping amount of $11.5 \%$ showed the best performance. There was no distinct peak shift between Cs-N/C-600 and Cs-N/C-800, so we inferred that stable coordination of cesium species and carbon was already formed at the temperature of $600{ }^{\circ} \mathrm{C}$. However, the structure could be destroyed as cesium atoms tend to evaporate when the temperature rises above $800^{\circ} \mathrm{C}$ (Fig. S3), which makes $800{ }^{\circ} \mathrm{C}$ the most suitable pyrolysis temperature.

The high-resolution XPS C $1 s$ (Fig. 2e) spectra revealed changes in the electronic structure of the carbon. The deconvolution of the $\mathrm{C} 1 \mathrm{~s}$ peak included the $\mathrm{C}-\mathrm{C} / \mathrm{C}=\mathrm{C}(284.8 \mathrm{eV})$, $\mathrm{C}-\mathrm{O} / \mathrm{C}-\mathrm{N}(286.8 \mathrm{eV})$ bonding moieties, and $(\mathrm{C}=\mathrm{O} / \mathrm{C}=\mathrm{N})$ near $288.8 \mathrm{eV}$. Cs-N/C catalysts showed a similar $\mathrm{C} 1 \mathrm{~s}$ spectrum to $\mathrm{N} / \mathrm{C}$; no new peak appeared in the low binding energy region, demonstrating that the cesium atoms were not directly bonded to the carbon atoms. Nevertheless, the $\mathrm{C}-\mathrm{O} / \mathrm{C}-\mathrm{N}$ peak shifted to the lower binding energy. There are two possible explanations for this phenomenon: cesium atoms infused electrons into carbon atoms through the $\mathrm{C}-\mathrm{O} / \mathrm{C}-\mathrm{N}$ bond or the presence of cesium atoms led to the loss of oxygen or nitrogen atoms on the carbon skeleton.

A comparison of $\mathrm{N} 1 s$ spectra for $\mathrm{Cs}-\mathrm{N} / \mathrm{C}$ and N/C is shown in Fig. 2(f). The XPS results suggested that the high-resolution $\mathrm{N} 1 \mathrm{~s}$ spectrum could be deconvoluted into four types: $398.4 \pm$ $0.2,400.0 \pm 0.2,401.0 \pm 0.2$, and $402.0 \pm 0.2 \mathrm{eV}$, corresponding to pyridinic $\mathrm{N}$, pyrrolic $\mathrm{N}$, graphitic $\mathrm{N}$, and oxidized $\mathrm{N}$, respectively [18]. An essential feature of Cs-N/C was that the pyridinic $\mathrm{N}$ peak split. A component emerged at binding energy about 0.5 $\mathrm{eV}$ lower than the main peak of pyridinic $\mathrm{N}$, which was fitted to Cs-N bonds that were observed in previously reported works [19]. An obvious Cs-N appeared in N $1 s$ spectra, whereas no $\mathrm{Cs}-\mathrm{O}$ bond could be found in $\mathrm{O} 1 \mathrm{~s}$ deconvolution, showing that the cesium atoms were coordinated with nitrogen atoms [20]. In summary, cesium coordinated with the nitrogen atom at defect sites to realize further electronic regulation of $\mathrm{N}$-doped carbon. The possible structure is provided in Fig. S15. In short, cesium carbonate is electron-injection material [21]. Cesium atoms bonded with nitrogen atoms and injected electrons into the carbon conjugate structure, increasing the electron density 

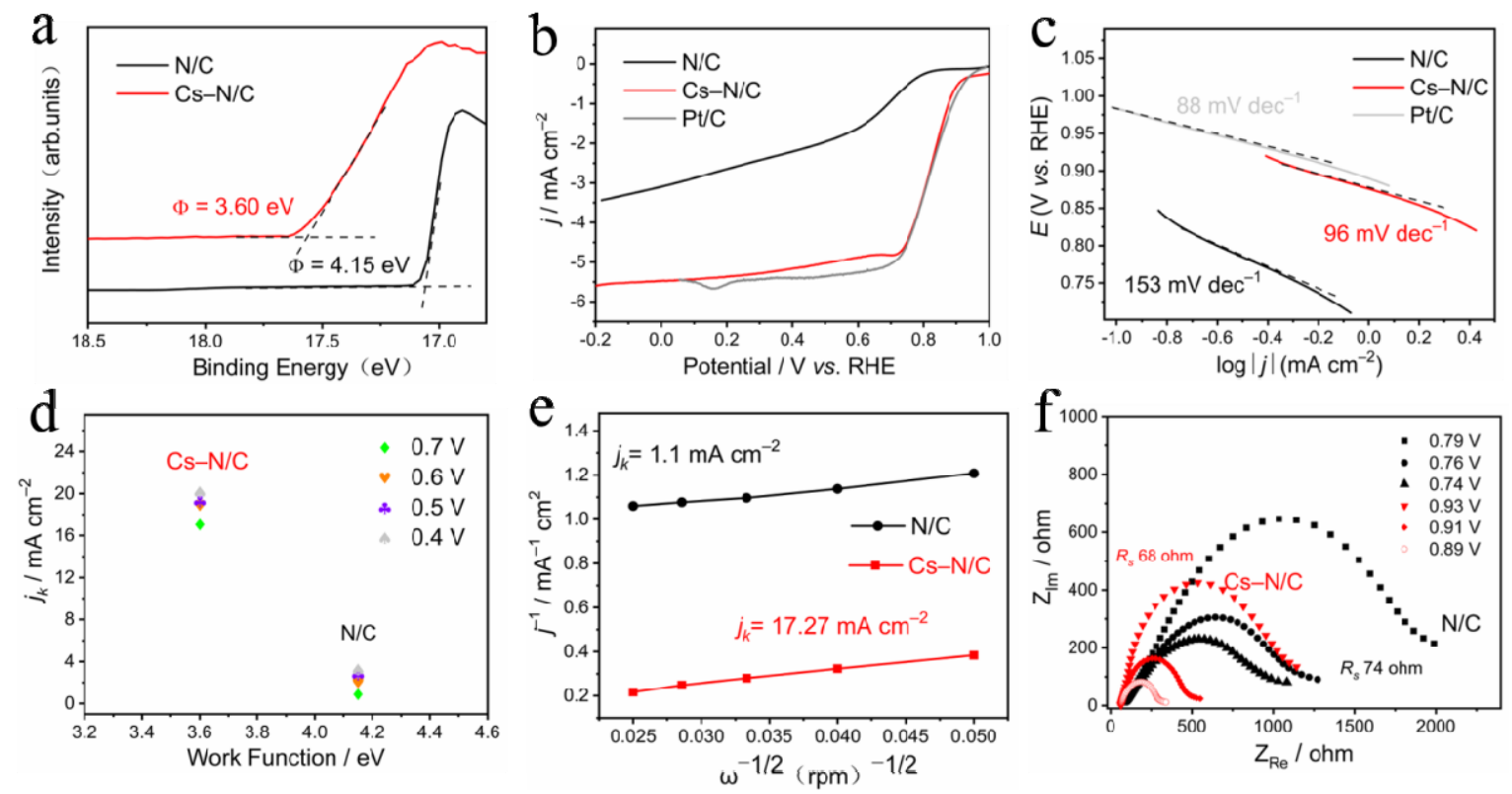

Fig. 3. (a) The UPS spectra of Cs-N/C and N/C; (b) ORR polarization curves of Cs-N/C, N/C and Pt/C; (c) Tafel plots of Cs-N/C, N/C and Pt/C; (d) Correlation of $j_{\mathrm{k}}$ of $\mathrm{Cs}-\mathrm{N} / \mathrm{C}$ and N/C at various potentials with their work function values; (e) Koutecky-Levich plots at $0.7 \mathrm{~V}$ of Cs-N/C and N/C; (f) Nyquist plots of Cs-N/C at $0.79,0.76,0.74 \mathrm{~V}$ and $\mathrm{N} / \mathrm{C}$ at the potential of $0.93,0.91,0.89 \mathrm{~V}$ vs RHE.

of the carbon plane. The electron density on the carbon surface increased and the work function decreased, which is beneficial to the ORR.

The lowered work function was detected by ultraviolet photoemission spectroscopy (UPS) (Fig. 3(a)), which has been widely applied to determine the work function of certain materials in many works [22]. The onset point of the UPS spectra in $\mathrm{Cs}-\mathrm{N} / \mathrm{C}$ was $16.95 \mathrm{eV}$, suggesting that the work function was $3.6 \mathrm{eV}$. The result was consistent with Kim's work, which reduced the work function of the graphene from 4.25 to $3.4 \mathrm{eV}$ using $\mathrm{Cs}_{2} \mathrm{CO}_{3}$ [15]. The N/C exhibited a work function of approximately $4.15 \mathrm{eV}$, similar to the results of previously reported $\mathrm{N}$-doped carbon materials [23]. There was a noticeable shift of secondary electron cutoff toward lower kinetic energy or a significant reduction of the work function after cesium-doping. Cesium, a notable low-work-function material, injects electrons into surrounding carbon atoms and moves the Fermi level closer to the vacuum level, thus reducing the work function [24].

To investigate the impact of reduced work function on the electrocatalytic performance on ORR, cyclic voltammogram tests were performed in $\mathrm{N}_{2}$ - or $\mathrm{O}_{2}$-saturated $0.1 \mathrm{M} \mathrm{KOH}$ (Fig. S9). In the same voltage window, only a featureless quasi-rectangular voltammogram was observed on both catalysts in the $\mathrm{N}_{2}$-saturated solution. However, a notable reduction process was apparent at $0.76 \mathrm{~V}$ vs RHE in the $\mathrm{O}_{2}$-saturated solution for $\mathrm{Cs}-\mathrm{N} / \mathrm{C}$, while $\mathrm{N} / \mathrm{C}$ showed greater negative peak potential ( $0.65 \mathrm{~V}$ vs RHE). Linear sweeping voltammetry (LSV) measurements were recorded on a rotating disk electrode with a rotation rate of $1600 \mathrm{rpm}$ using $\mathrm{O}_{2}$-saturated $0.1 \mathrm{M} \mathrm{KOH}$ at a scan rate of $10 \mathrm{mV} \mathrm{s}^{-1}$. As shown in Fig. 3(b), the Cs-N/C showed an onset potential of $0.91 \mathrm{~V}$ and a halfway potential of
$0.83 \mathrm{~V}$, both of which were comparable to Pt/C (0.95 and 0.83 V) and exceeded most carbon-based materials [25,26]. The Tafel plots were obtained from the polarization curves. The Cs-N/C had a Tafel slope of $92 \mathrm{mV} \mathrm{dec}^{-1}$, much smaller than that of the N/C (138 $\left.\mathrm{mV} \mathrm{dec}^{-1}\right)$, and close to that of the Pt/C (88 $\mathrm{mV} \mathrm{dec}^{-1}$ ), suggesting greatly improved ORR kinetics in the Cs-N/C electrocatalyst due to activated reaction sites caused by the lowered work function (Fig. 3(c)). To determine the kinetic limiting current density $\left(j_{\mathrm{k}}\right)$, the LSV curves of ORR of Cs-N/C and N/C were measured at different rotation rates, from 400 to 1600 rpm (Figs. S10 and S11). According to Cheon's work, the kinetic current densities are inversely proportional to the work functions of doped carbon [12]. As shown in Fig. 3(d), the lower work function corresponded to higher kinetic current densities. In particular, the $j_{k}$ value of Cs-N/C was calculated to be 17.47 $\mathrm{mA} \mathrm{cm}{ }^{-2}$ at $0.7 \mathrm{~V}$, much higher than that of $\mathrm{N} / \mathrm{C}\left(1.92 \mathrm{~mA} \mathrm{~cm}^{-2}\right)$ (Fig. 3(e)). The low-work-function carbon has a lower energetic barrier for donating electrons from the surface of the catalyst to the adsorbed oxygen, thereby facilitating the formation of the $\mathrm{OOH}^{*}$ species [12], which in turn is the rate-determining step in the ORR [27].

Fig. S12(a) presents the disk and ring currents for Cs-N/C. The electron transfer number $(n)$ was approximately 4 for in the potential range of $0-0.7 \mathrm{~V}$, indicating that the ORR on Cs-N/C proceeded with an ideal four-electron reaction pathway. The $\mathrm{H}_{2} \mathrm{O}_{2}$ yield of the Cs-N/C was calculated to be less than 5\% (Fig. S12(b)). Furthermore, as displayed in Fig. S13, the Cs-N/C exhibited almost no current reduction retention after $20000 \mathrm{~s}$ in the chronoamperometry test. Meanwhile, the Cs-N/C also showed better methanol tolerance than commercial Pt/C (Fig. S13). Those results demonstrated the outstanding ORR performance of Cs-N/C. 
Meanwhile, the in-situ electrochemical impedance spectroscopy (EIS) measurements were performed at various potentials to investigate further the catalytic kinetics of Cs-N/C and N/C. Fig. 3(f) shows the Nyquist plots of Cs-N/C at 0.93, $0.91,0.89 \mathrm{~V}$, and N/C at 0.79, 0.76, 0.74 V (vs RHE). Fig. S14(a) shows the equivalent circuit and Fig. S14(b) shows the fitting equation of the Nyquist plots. The semicircular diameter of the EIS curve stands for $R_{\mathrm{ct}}$, contacting the interfacial charge transfer reaction, and the intercept on the abscissa represents the solution resistance $\left(R_{\mathrm{s}}\right)$. When the test conditions remain constant, the semicircular diameter of the EIS curve can directly reflect the conductivity of the electrode material [28]. The Cs-N/C possessed smaller $R_{\mathrm{ct}}$ and smaller $R_{\mathrm{S}}$ than N/C. One possible reason is that $\mathrm{N}$ doping is n-type doping, which increases the electron concentration in carbon and makes the electron the leading carriers (rather than holes) [29]. Further cesium doping resulted in the injection of electrons, which greatly enlarged the carrier concentration and thus increased the conductivity of the electrode material. This phenomenon once again verified the electron injection of cesium atoms to carbon atoms.

\section{Conclusions}

In conclusion, the work function of $\mathrm{N}$-doped carbon was regulated through cesium doping to improve electrocatalytic performance in oxygen reduction. Mapping and XPS confirmed the formation of a Cs-N/C structure, while Raman and UPS revealed the strongly regulated electronic state of carbon. Cesium atoms bonded with nitrogen atoms changed the work function of the carbon surface, and ultimately facilitated the adsorption of intermediates during ORR. The ORR activity of N-doped carbon was greatly improved using this strategy. Cesium was used as an electronic modifier for the first time, and this novel strategy seems promising for future applications in energy conversion and storage.

\section{Electronic supporting information}

Supporting information is available in the online version of this article.

\section{References}

[1] K. Gong, F. Du, Z. Xia, M. Durstock, L. Dai, Science, 2009, 323, 760-764.

[2] S. Sun, F. Jaouen, J.-P. Dodelet, Adv. Mater., 2008, 20, 3900-3904.

[3] L. Qu, Y. Liu, J.-B. Baek, L. Dai, ACS Nano, 2010, 4, 1321-1326.

[4] H. Zhao, C. C. Weng, J. T. Ren, L. Ge, Y. P. Liu, Z. Y. Yuan, Chin. J. Catal., 2020, 41, 259-267.

[5] H. G. R. Monestel, I. S. Amiinu, A. A. González, Z. Pu, B. Mousavi, S. Mu, Chin. J. Catal., 2020, 41, 839-846.

[6] K. Chen, S. Ci, Q. Xu, P. Cai, M. Li, L. Xiang, X. Hu, Z. Wen, Chin. J. Catal., 2020, 41, 858-867.

[7] L. Zhang, Z. Xia, J. Phys. Chem. C, 2011, 115, 11170-11176.

[8] N. D. Lang, W. Kohn, Phys. Rev. B, 1971, 3, 1215-1223.

[9] C. G. Vayenas, S. Bebelis, S. Ladas, Nature, 1990, 343, 625-627.

[10] S. Liu, X. F. Lu, J. Xiao, X. Wang, X. W. Lou, Angew. Chem. Int. Ed., 2019, 58, 13828-13833.

[11] S. Ni, Z. Li, J. Yang, Nanoscale, 2012, 4, 1184-1189.

[12] J. Y. Cheon, J. H. Kim, J. H. Kim, K. C. Goddeti, J. Y. Park, S. H. Joo, J. Am. Chem. Soc., 2014, 136, 8875-8878.

[13] H. Shin, N. Kang, D. Kang, J. S. Kang, J. H. Ko, D. H. Lee, S. Park, S. U. Son, Y.-E. Sung, ChemElectroChem, 2018, 5, 1905-1913.

[14] J. D. Lin, C. Han, F. Wang, R. Wang, D. Xiang, S. Qin, X.-A. Zhang, L. Wang, H. Zhang, A. T. S. Wee, W. Chen, ACS Nano, 2014, 8, 5323-5329.

[15] K. C. Kwon, K. S. Choi, B. J. Kim, J.-L. Lee, S. Y. Kim, J. Phys. Chem. C, 2012, 116, 26586-26591.

[16] S. Van den Berghe, J. P. Laval, B. Gaudreau, H. Terryn, M. Verwerft, J. Nucl. Mater., 2000, 277, 28-36.

[17] J.-H. Huang, J.-H. Fang, C.-C. Liu, C.-W. Chu, ACS Nano, 2011, 5, 6262-6271.

[18] T. Liu, S. Feng, J. Huo, Q. Li, C. Xie, S. Wang, ChemCatChem, 2018, $10,4562-4568$.

[19] H. Ding, Y. Gao, Appl. Phys. Lett., 2005, 86, 213508.

[20] E. A. Podgornov, I. P. Prosvirin, V. I. Bukhtiyarov, J. Mol. Catal. A, 2000, 158, 337-343.

[21] J.-H. Lee, D.-S. Leem, J.-J. Kim, Org. Electron., 2010, 11, 486-489.

[22] E. R. Kötz, H. Neff, K. Müller, J. Electroanal. Chem. Interf. Electrochem., 1986, 215, 331-344.

[23] W. J. Lee, J. Lim, S. O. Kim, Small Methods, 2017, 1, 1600014.

\section{Graphical Abstract}

Chin. J. Catal., 2021, 42: 938-944 doi: 10.1016/S1872-2067(20)63701-9

\section{Regulating carbon work function to boost electrocatalytic activity for the oxygen reduction reaction}

Yazhi Cai, Li Tao, Gen Huang, Nana Zhang, Yuqin Zou *, Shuangyin Wang Hunan University

The cesium-doping could regulate the work function of $\mathrm{N}$-doped carbon and boost the electrocatalytic activity for the ORR.

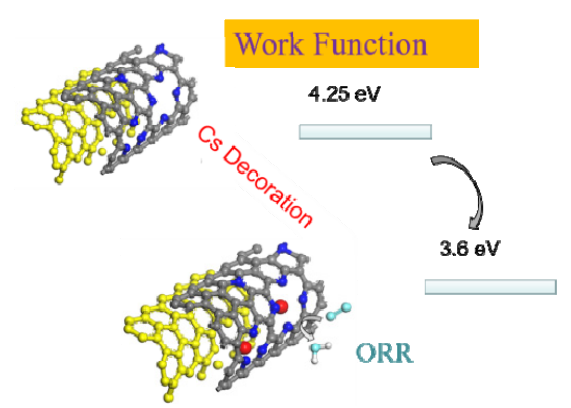


[24] C.-I. Wu, C.-T. Lin, Y.-H. Chen, M.-H. Chen, Y.-J. Lu, C.-C. Wu, Appl. Phys. Lett., 2006, 88, 152104.

[25] C. Han, J. Wang, Y. Gong, X. Xu, H. Li, Y. Wang, J. Mater. Chem. A, 2014, 2, 605-609.

[26] C. Han, S. Wang, J. Wang, M. Li, J. Deng, H. Li, Y. Wang, Nano Res.,
2014, 7, 1809-1819.

[27] Y. Jiao, Y. Zheng, M. Jaroniec, S. Z. Qiao, J. Am. Chem. Soc., 2014, $136,4394-4403$.

[28] M.-J. Uddin, S.-J. Cho, Sustain. Energy Fuels, 2018, 2, 1458-1462.

[29] J. Robertson, C. A. Davis, Diam. Relat. Mater., 1995, 4, 441-444.

\title{
调控碳材料的功函数以大幅度提升其电催化氧还原性能
}

\author{
蔡雅芝, 陶 李, 黄 根, 张娜娜, 邹雨芹“, 王双印
}

湖南大学化学化工学院, 湖南省石墨烯材料与器件重点实验室, 化学生物传感与化学计量学国家重点实验室, 湖南长沙410082

\begin{abstract}
摘要: 氧的电催化还原反应是燃料电池装置与金属空气电池的阴极反应, 具有重大的研究意义. 在众多的非铂催化剂中, 碳材料因其低廉的价格以及独特的物理化学性质受到了广泛的关注. 自从发现氮掺杂的碳纳米阵列具有优异的氧还原活 性后, 不同类型的氮掺杂的碳也得到了深入研究. 例如近年来兴起的由金属有机框架衍生的氮掺杂的碳材料, 兼具丰富的 氮位点及良好的三维结构. 氮的掺杂对碳原子具有电子调控的作用, 是其高氧还原活性的根本原因. 本文对金属有机框架 衍生的氮掺杂的碳材料进行进一步的电子结构的优化, 以提升催化性能.

功函是电子逸出表面所需的最少的能量, 是材料的电子结构性质之一, 其对氧还原反应的影响也有报道, 早期以理论 计算为基础, 探究氧气分子在碳材料表面的解离能与氮掺杂的碳的表面功函的关系, 后续则采用开尔文探针显微镜, 直接 测量了不同元素掺杂的碳表面功函, 并建立起功函与氧还原动力学的线性关系. 本文通过控制碳材料的功函来调节其电 子结构. 铯是一种经典的给电子物质, 通过将电子注入到掺杂材料表面来降低其功函. 因此, 本文通过 $\mathrm{CsCO}_{3}$ 与 2 -甲基咪 唑、 $\mathrm{Zn}\left(\mathrm{NO}_{3}\right)_{2}$ 搬烧形成铯修饰的氮掺杂碳. 电镜及XRD均观察不到所得材料中铯的存在, 证明碳层中无大颗粒团聚的铯物 种. EDS元素分布图表明, 铯在碳层中呈原子级均匀分布. Raman谱结果表明, 碳的G带发生明显的位置偏移, 证明其面内 电子结构发生了明显的改变. XPS结果证明铯成功与氮原子配位, 通过铯氮键将电子注入到碳骨架. UPS则最终显示, 经过 铯的修饰, 碳表面功函从 $4.25 \mathrm{eV}$ 下降到 $3.6 \mathrm{eV}$. 表面功函的降低有利于氧气分子的解离, 也调节 $\mathrm{OOH}^{*}$ 中间体的吸附, 使其 吸附的自由能更接近最优值. 材料改性后氧还原性能明显提升, 起始电位达到 $0.91 \mathrm{~V} v s \mathrm{RHE}$, 半波电位达到 $0.83 \mathrm{~V} v s$ RHE, 均接近商业 $\mathrm{Pt} / \mathrm{C}$ 催化剂. 氧还原反应的动力学电流密度随功函的降低而增大, 验证了前人的结论. 本文提供了一个较为新 颖的电子结构调控策略, 为设计新的氧还原催化剂提供了新的思路.
\end{abstract}

关键词: 铯掺杂; 氮掺杂的碳; 电子调控; 功函; 氧还原反应

收稿日期: 2020-05-11. 接受日期: 2020-07-06. 上网日期: 2020-11-22.

*通讯联系人. 电子信箱: yuqin_zou@hnu.edu.cn

基金来源：中央高校基础研究基金(531118010127); 国家自然科学基金(21902047, 51402100, 21825201, 21573066, 21805080); 湖 南省自然科学基金(2016TP1009).

本文的电子版全文由Elsevier出版社在ScienceDirect上出版(http://www.sciencedirect.com/science/journal/18722067). 